Itinéraires Itinéraires

Littérature, textes, cultures

\title{
Postérités du cut-up dans la chanson rock
} (1970-2000)

Posterities of Cut-Up in Rock Songs (1970-2000)

\section{Clémentine Hougue}

\section{OpenEdition}

Journals

Édition électronique

URL : http://journals.openedition.org/itineraires/3889

DOI : $10.4000 /$ itineraires.3889

ISSN : 2427-920X

Éditeur

Pléiade

Référence électronique

Clémentine Hougue, «Postérités du cut-up dans la chanson rock (1970-2000) », Itinéraires [En ligne], 2017-3 | 2018, mis en ligne le 15 juin 2018, consulté le 23 avril 2019. URL : http://

journals.openedition.org/itineraires/3889; DOI : 10.4000/itineraires.3889

Ce document a été généré automatiquement le 23 avril 2019

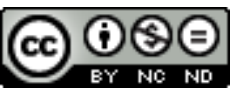

Itinéraires est mis à disposition selon les termes de la licence Creative Commons Attribution - Pas d'Utilisation Commerciale - Pas de Modification 4.0 International. 


\title{
Postérités du cut-up dans la chanson rock (1970-2000)
}

\author{
Posterities of Cut-Up in Rock Songs (1970-2000)
}

Clémentine Hougue

1 Procédé de collage littéraire, le cut-up est créé en 1959 par William Burroughs et Brion Gysin : il consiste en un découpage puis un réagencement de fragments de textes issus de sources diverses (œuvres littéraires, coupures de presse, textes personnels, etc.). Emprunté au collage pictural, cette technique d'écriture prolonge et enrichit l'expérimentation avant-gardiste (notamment dadaïste) par une fragmentation radicale, un mode de recomposition mécanique, mais surtout une extension de son usage à la forme romanesque. La «trilogie Nova" (The Soft Machine, 1961, The Ticket That Exploded, 1962 et Nova Express, 1964) est une œuvre de science-fiction qui relate, dans une prose instable et morcelée, un conflit interplanétaire opposant le complot Nova, qui manipule les esprits par la diffusion d'images et de messages, et des résistants, disloquant ces messages par cut-up, pour en court-circuiter les manipulations. C'est donc une véritable guerre du langage qui se joue, aussi bien sur le plan du texte, où syntaxe et narration se délitent, que dans la diégèse, où le cut-up apparaît comme stratégie de guérilla résistante.

2 La dimension expérimentale du procédé constitue le soubassement d'une radicalité idéologique qui met en question les structures mêmes du langage et de la communication. La poétique de la rupture à l'œuvre dans le cut-up permet à la fois une libération du sens, émancipé de la linéarité continue de la langue, et la mise en œuvre d'une politique de l'écriture : briser le langage, c'est court-circuiter le flot de messages diffusés dans les sociétés de l'information. Le cut-up, fort de ces implications esthétiques et politiques, marque profondément la création contemporaine dès le début des années 1970: de nombreux artistes vont revendiquer l'influence de Burroughs et de sa technique dans leurs propres créations. Ces développements du cut-up ont pour particularité d'intervenir sous des formes et dans des espaces divers: dans la littérature, naturellement (J.G. Ballard, Kathy Acker, et en France, Claude Pélieu, Jean-Jacques Schuhl, Christian Prigent, etc.), dans la poésie sonore et performée (comme Bernard Heidsieck ou John Giorno), mais aussi, de façon plus inattendue, dans des musiques populaires comme le 
rock et les nombreux courants qui en dérivent (glam rock, punk, grunge, rock alternatif, etc.).

Quelles sont les modalités de ce transfert? Qu'implique la mobilisation d'un procédé aussi radicalement expérimental que le cut-up dans le champ de la chanson populaire ? Quelles mutations le cut-up, procédé hérité des avant-gardes, subit-il en étant réinvesti par les artistes de la contre-culture ? Les enjeux poétiques, esthétiques et politiques du cut-up, ainsi que l'histoire de sa réception, permettent de poser les fondements de cette réflexion.

\section{Le cut-up : enjeux et réception d'une écriture expérimentale}

4 Dès 1959, Burroughs, sous l'influence des travaux du peintre Brion Gysin, radicalise sa recherche de démantèlement de la continuité textuelle et narrative. Le cut-up, dans son principe général, consiste à découper de manière systématique deux textes au moins et à les agencer suivant un ordre prédéterminé pour composer un nouveau texte. Cette technique mécanique produit alors un texte mutilé, fragmenté à l'extrême, dont voici un exemple, tiré de Nova Express (Burroughs [1967] 1994 : 407) :

Film éclaté loin dans l'allée métallique $\mathrm{Oz}$ - Cherchez n'importe où main morte - Os phosphorescents - Source Froide placenta de cet hôpital - Lancinements d'amputation - Couteau à pain dans le cœur garçons taxis payés - Si je savais je veux bien regarder n'importe où - Vaut rien moi - viens Vendledi ${ }^{1}$ - Vent malade identité s'estompant - La fumée c'est tout - Nous interceptons à travers les portes sombres émeutiers - Crâne déplumé - Chair badigeonnée - Cinq fois nous l'avons créé de la poussière - consumée par des feux métalliques lents - Odeur d'essence enveloppe le dernier électricien et je me suis réveillé avec les renseignements ténébreux des morts $-[. . .]^{2}$.

5 La méthode du cut-up, expliquée dans "The Cut-Up Method of Brion Gysin » (Euvre Croisée, [1961] 1976), ne s'applique pas qu'au texte : Burroughs et Gysin l'emploient sur tous les supports de diffusion du langage et de l'image: bandes magnétiques, films, photographies, etc.

6 Le caractère expérimental du cut-up tient à la dimension mécanique du procédé, qui rend la production textuelle aléatoire. Appliquée à la forme romanesque, la technique s'amplifie d'un procédé d'autogénération du texte : un cut-up peut être de nouveau coupé et associé à un nouveau texte, ou à un autre texte en cut-up. On voit ainsi réapparaître, tout au long de la trilogie, les mêmes fragments, combinés différemment. La matière textuelle de la trilogie Nova atteint par endroits un degré de fragmentation qui ne permet pas d'identifier la source des fragments, comme le souligne Noëlle Batt (1975 : 138) :

Les mots avancent, reculent, en une valse effrénée. Une véritable mosaïque est ainsi constituée, mosaïque d'images éclatées qui se bousculent bien plus que dans les deux cas précédents dans la mesure où la source n'est pas localisée et où les membres de phrases qui viennent ainsi de tous les points du chapitre - trois lignes ou deux pages plus haut - sont des membres de phrases très courts, parfois réduits à un seul mot.

7 L'extrême fragmentation de l'écriture burroughsienne est en outre travaillée par le motif science-fictionnel d'un complot interplanétaire, la Conspiration Nova : celle-ci manipule les esprits par une intoxication aux images et au langage, qui agissent comme une drogue. Enfermés dans un «film-réalité », une réalité truquée, fabriquée en studio, les individus 
intoxiqués n'ont d'autre choix que de participer à cet ersatz de réel. Le seul moyen pour lutter contre la Conspiration Nova est de couper les lignes de communication qui la maintiennent en place; ainsi, le cut-up est à la fois ce qui manifeste le chaos, en perturbant la syntaxe et brouillant les repères, et, dans le même temps, ce qui offre le remède à l'intoxication. Le texte prend alors un caractère performatif dans la mesure où la trilogie est émaillée d'appels à couper les lignes de mots et d'images, à appliquer le cutup, en même temps que se déroule, sous les yeux du lecteur, le texte fragmenté par cette même technique.

8 La performativité du cut-up, reposant sur le fait que le texte dévoile son mode de composition en même temps qu'il tisse sa diégèse autour de ce procédé, est amplifiée par des textes programmatiques, dans lesquels le cut-up est présenté non plus comme une technique littéraire, mais comme un moyen de résistance contre l'omniprésence des médias : «The Invisible Generation » (1966) et « Electronic Revolution » (1971) sont deux textes qui prônent, par l'emploi du cut-up, le brouillage systématique des informations. Dans ces deux manuels de guérilla urbaine, la portée politique de l'usage du cut-up est explicite: plus qu'une technique d'écriture, il est, comme dans la trilogie, le moyen de mise en œuvre d'une "révolution électronique » contre le langage-virus qui conditionne les individus et maintient l'ordre établi. La volonté de briser le langage et de libérer le sens, de s'émanciper des messages préfabriqués par la société des médias, procède d'une technique de combat utilisable par le plus grand nombre («Les cut-ups sont pour tous » écrit Burroughs dans «The Cut-Up Method of Brion Gysin »; [1961] 1976 : 34). Le cut-up est donc un moyen de retourner le flux médiatique contre lui-même en court-circuitant les messages qu'il transporte : en ce sens, il se rapproche du détournement situationniste, ce «langage fluide de l'anti-idéologie» (Debord [1954] 2006: 854), dans la mesure où le collage est envisagé comme une praxis sociale, et destiné à une utilisation dans la vie quotidienne.

Le cut-up est historiquement lié aux pratiques d'avant-garde : le collage pictural, dont les procédés de collage littéraire s'inspirent, est issu du cubisme, puis a été repris par Dada, les futuristes russes et italiens puis les surréalistes. Il s'inscrit ainsi dans la vaste histoire du collage moderniste. Burroughs considère d'ailleurs que « Pour faire un poème dadaïste ${ }^{3}$ » de Tristan Tzara (1918) est un des premiers cut-ups ; il fait du poète dadaïste la figure tutélaire de "The Cut-Up Method of Brion Gysin », comme en témoignent les premières lignes de ce texte-manifeste: "Lors d'une réunion surréaliste des années 1920, Tristan Tzara, l'homme de nulle part, proposa de composer un poème sur-le-champ en tirant des mots d'un chapeau. Une algarade s'ensuivit et le théâtre fut saccagé » (Burroughs [1961] 1976 : 32). Le cut-up représente ainsi un prolongement américain de ces avant-gardes européennes : il partage notamment avec le dadaïsme une véritable violence faite à la représentation (et à la matière textuelle), qui lui vaut une réception publique chaotique.

En effet, la trilogie Nova est, à sa publication, perçue comme "une impasse expérimentale» (Lydenberg et Skerl 1991: 8) : une impasse pour le lecteur, malmené aussi bien par les injonctions à « couper les lignes » que par les méandres des fragments ; une impasse pour la diégèse elle-même, qui s'achève sur une profonde indétermination, car il est impossible de savoir qui, du complot ou des résistants, remporte cette guerre médiatique. Mais progressivement, la trilogie Nova (et plus globalement le cut-up) va être lue comme une réflexion sur les structures du langage et de la communication, et non plus seulement comme la destruction provocatrice de la forme romanesque. 
11 L'évolution de la critique littéraire américaine, sous l'influence de la French Theory, permet cette nouvelle réception du cut-up, que Robin Lydenberg et Jennie Skerl (1991: 8) expliquent ainsi :

Il est revenu aux critiques des années 1970 et 1980 de prendre les cut-ups au sérieux et d'expliquer en détail leur but, leur structure et leurs effets. La révolution poststructuraliste dans les études littéraires a conduit à une relecture des fictions de Burroughs en tant que textes plutôt qu'en tant que messages, et a apporté une justification à ces mêmes techniques qui n'avaient jusque-là rencontré qu'incompréhension et désapprobation.

Le développement de nouvelles méthodes d'analyse littéraire dans les années 1970 a permis une profonde mutation de la réception de Burroughs : d'expérimentateur dépravé et illisible, il est devenu l'audacieux metteur en scène des théories du déconditionnement, un nouveau penseur du langage.

Dans le sillage de cette nouvelle lecture du cut-up, des événements pluridisciplinaires vont contribuer à l'évolution de la réception de Burroughs: par exemple en 1978, le philosophe Sylvère Lotringer, enseignant à Columbia, réunit les figures principales de la contre-culture de l'époque lors de la « Nova Convention », une série de représentations en hommage à Burroughs. La manifestation, explicitement placée sous l'égide de Burroughs, réunit (outre l'auteur lui-même et les membres de la Beat Generation Gysin, Ginsberg et Orlovsky), les musiciens Laurie Anderson, John Cage, Keith Richards, Philip Glass, Frank Zappa et Patti Smith. Ainsi, alors qu'une légitimation universitaire se construit progressivement, un processus simultané de légitimation populaire s'engage, et la guérilla du langage qu'opère le cut-up va peu à peu s'infiltrer dans les textes des chansons rock.

\section{Postérité(s) rock du cut-up}

En 1973, après sept ans passés à Londres, Burroughs s'installe à New York, sur la Bowery Street, dans un quartier fréquenté par de nombreux artistes de la scène rock et punk rock. Alors qu'il a été jusque-là un auteur marginal, taxé de pornographie et lu essentiellement dans les milieux underground, il va bénéficier d'une réception plus ample, au contact d'une contre-culture américaine bien plus vaste que ne l'étaient les cercles artistiques expérimentaux dans lesquels il évoluait jusque-là.

Le cut-up, essentiellement transmédiatique, a été très tôt été utilisé par Burroughs et Gysin pour produire des œuvres sonores, suivant la technique du splice-in, ou « épissure ", qui consiste en une application du cut-up à la bande magnétique. La réception de William Burroughs dans les milieux de la musique rock est notamment passée par l'album Call me Burroughs, qui comporte ses premiers cut-ups sonores, réalisés à Paris au tournant des années 1950 et 1960 ; Barry Miles (1995) raconte à ce propos :

En plein milieu des années 1960, Call me Burroughs était un disque essentiel. Tous les Beatles en avaient un exemplaire (Paul McCartney a inclus Bill sur la pochette de Sgt Pepper's Lonely Heart Club Band). Le marchand d'art Robert Fraser en a acheté dix exemplaires pour les donner à ses amis, comme Brian Jones et Mick Jagger. Les distributeurs de Marianne Faithfull et Keith Richards en avaient des exemplaires, ainsi que de nombreux peintres et écrivains.

16 Les cut-ups sonores, bien qu'étant des œuvres expérimentales formellement très éloignées de la musique populaire, séduisent donc des personnalités ayant à l'époque un succès public de grande ampleur. Aussi les pratiques héritées de cette méthode vont-elles 
se développer dans de nombreux champs musicaux (free-jazz, musiques industrielles et électroniques) et trouver un écho dans des techniques de composition musicale inédites, comme le sampling. Mais le cut-up reposant fondamentalement sur un travail de déconstruction de la langue, c'est au texte des chansons rock que nous nous intéresserons ici. À travers quelques exemples représentatifs et sans prétendre à l'exhaustivité, il s'agira d'examiner et d'interroger la propagation d'une écriture expérimentale dans le champ populaire du rock et de ses prolongements punk et alternatif.

\section{Le rock des années 1970 : The Rolling Stones et David Bowie}

17 Les artistes de la scène rock des années 1970 ayant fait référence à l'univers des romans de William Burroughs sont nombreux : de Patti Smith (notamment sur l'album Horses) à Iggy Pop, en passant par Lou Reed ou Franck Zappa, la réception de l'auteur est considérable dans la constellation rock. Mais deux cas semblent plus particulièrement intéressants : l'emploi de la technique du cut-up par les Rolling Stones et par David Bowie.

The Rolling Stones n'ont utilisé le procédé de Burroughs qu'une seule fois, pour la chanson "Casino Boogie» (Exile on Main Str., 1972). Mick Jagger et Keith Richards, compositeurs de ce titre, ont récemment révélé l'usage de cette technique dans une interview donnée au magazine britannique Uncut Magazine en avril 2010, à l'occasion de la réédition de Exile on Main Str. Mick Jagger est interrogé par David Cavanagh (2010:51) sur le sens des paroles « million dollar sad ». Le leader de The Rolling Stones répond alors :

Cette chanson a été faite en cut-ups. Dans le style de William Burroughs, tu vois.

"Million dollar sad" ne veut rien dire. On l'a faite à L.A., en studio. On a simplement écrit des phrases sur des morceaux de papier et on les a coupés. C'est ingénieux. Le style Burroughs. Et puis vous les jetez dans un chapeau, les piochez et les assemblez en vers. On ne l'a fait que pour un morceau, mais ça a marché. On l'a probablement fait parce qu'on n'arrivait pas à écrire.

La musique de ce morceau est de facture classique ; il s'agit d'un blues orchestré avec guitare électrique, basse, batterie, piano électrique et saxophone. Mais le texte révèle en effet des ruptures syntaxiques et sémantiques proches du cut-up. Toutefois, le procédé d'écriture que décrit ici Mick Jagger est en fait strictement celui que décrit Tristan Tzara dans «Pour faire un poème dadaïste ", plus qu'un processus de combinaison comme le cut-up. En effet, les «mots tirés d'un chapeau» de Tzara reposent totalement sur le hasard, quand le cut-up procède d'une combinatoire prédéterminée et d'un principe d'autogénération. Cet amalgame, commun à la plupart des artistes rock, révèle l'influence de l'écrivain américain : une chanson créée en piochant au hasard des mots découpés n'est pas associée à un poème dadaïste, mais à un cut-up burroughsien. Cette assimilation rend compte de la fonction charnière du cut-up entre l'avant-garde et la contre-culture, point sur lequel nous reviendrons.

Contrairement à la révélation tardive de l'utilisation du procédé par Mick Jagger, David Bowie a très tôt revendiqué l'influence de l'écriture burroughsienne. Dès 1972, il aurait utilisé le cut-up, comme en témoigne le documentaire Cracked Actor (1975) où Bowie, ciseaux en main, découpe des fragments d'un texte personnel pour les recomposer, créant ainsi le titre "Moonage Daydream ", sur l'album The Rise and Fall of Ziggy Stardust and the Spiders from Mars. De même, la chanson «Blackout " (Heroes, 1977) a été composée suivant une méthode similaire, comme le prouve le collage présenté au Victoria and Albert Museum de Londres en 2013, à l'occasion de l'exposition des archives personnelles 
de l'artiste. C'est une technique d'écriture que l'artiste anglais emploie encore dans les années 1990, mais cette fois au moyen d'un logiciel, The Verbasizer, programme créé par son ami Ty Roberts. À la différence des Rolling Stones, Bowie fera ainsi un usage régulier du cut-up, qu'il réactualisera par l'emploi de l'outil informatique.

Bowie ne se limite pas à une utilisation mécanique du procédé : les thèmes abordés par l'artiste révèlent également des affinités avec l'univers burroughsien. Celui du voyage dans l'espace, omniprésent chez Bowie, peut être rapproché de la trame romanesque de la trilogie Nova, où des soldats androgynes, les "Garçons Filles Vénusiens », ne manquent pas d'évoquer le personnage de Ziggy Stardust, double fictif de David Bowie. Les paroles de «Life on Mars? (Hunky Dory, 1971), titre qui reprend également le motif du voyage interplanétaire, présentent une déconstruction telle qu'on pourrait y voir un cut-up : elles évoquent un homme ignorant qu'il est dans un spectacle à succès ("Wonder if he'll never know / He's in the best selling show »), et révèlent ainsi une inquiétude qui peut rappeler le « film-réalité » créé par la Conspiration Nova.

Le « cas Bowie » est une manifestation révélatrice de l'évolution de la réception du cutup : d'abord lors de la grande exposition des archives personnelles de l'artiste à Londres en 2013, puis au décès de l'artiste en janvier 2016, l'emploi qu'il a fait du cut-up est de plus en plus souvent mentionné dans la presse. L'apport de cette écriture expérimentale à l'œuvre d'un artiste majeur de la musique populaire contribue à la fois à singulariser le travail de Bowie et à populariser celui de Burroughs.

Plus globalement, le succès du cut-up dans les années 1970 peut s'expliquer par le psychédélisme en vogue dans le rock de cette époque (qui invite les auteurs-compositeurs à rechercher une déconstruction du texte qui corresponde à la déconstruction de la conscience et des perceptions lors de la prise de psychotropes), mais il est, plus profondément, le signe d'une déconstruction généralisée du sens: ce qui était déjà présent dans les démarches artistiques et littéraires depuis la fin du XIX ${ }^{\mathrm{e}}$ siècle - avec Rimbaud et Mallarmé, Cézanne puis Picasso, par exemple - s'est désormais installé dans la culture populaire. La massification de celle-ci s'accompagne d'une intégration de procédures auparavant réservées à l'avant-garde: le prolongement de la modernité - dont le collage est une invention - se fait jour dans la culture de masse. Et cette déstabilisation du sens propre au cut-up va faire de William Burroughs une référence dans un champ musical contestataire, hérité du rock : le punk.

\section{Le courant punk}

24 Lui-même auteur d'articles sur le rock et le punk, Burroughs devient une référence, au point qu'on le considère, à la fin des années 1970, comme le «parrain » du mouvement punk, étiquette que l'auteur refusait pourtant d'assumer. Burroughs tente d'expliquer cette filiation imposée, dans un entretien pour le journal punk rock Search \& Distroy en 1978 (Bockris 1981 : 127) :

Je ne suis pas un punk et je ne sais pas pourquoi on me considérerait comme le parrain du punk. Comment définir un punk? La seule définition du mot pourrait renvoyer à un jeune qui est simplement nommé «punk » parce qu'il est jeune, ou bien une sorte de petit délinquant. Dans ce sens, certains de mes personnages peuvent être considérés comme des punks, mais le mot n'existait tout simplement pas dans les années 50. [...] Je pense que le soi-disant mouvement punk est en fait une création des médias. J'ai cependant envoyé une lettre de soutien aux Sex Pistols quand ils ont sorti « God Save the Queen » en Angleterre, parce que j'ai toujours dit 
que ce pays n'avait aucune chance tant qu'il n'y aurait pas 20000 personnes disant «J'EMMERDE LA REINE ». Et je soutiens les Sex Pistols parce que c'est une critique nécessaire et constructive d'un pays ruiné. virulente de l'ordre établi et une mise en question brutale des pouvoirs en place, des thèmes centraux dans la trilogie Nova. Cependant, cet engouement pour Burroughs dépasse sans doute la dimension contestataire de son œuvre : il existe dans sa technique d'écriture une affinité structurelle avec l'esthétique punk, dans la mesure où le punk comme le cut-up utilisent l'un et l'autre les contraintes d'un genre (respectivement la musique populaire et le roman) pour les pulvériser de l'intérieur, comme le note le biographe Graham Caveney: "Que beaucoup d'artistes punk aient trouvé une affinité avec l'œuvre de Burroughs n'a rien de surprenant. Ils sont également emprisonnés dans des formes à travers lesquelles ils articulent leur évasion. La dissonance devient le cut-up de la pop music » (Caveney [1998] 1999 : 137). Le punk serait ainsi à la musique populaire ce que le cut-up est au roman : une entreprise de démantèlement des anciennes règles et de libération totale des formes.

Jello Biaffra fait partie de ces musiciens punk ayant revendiqué l'usage de cette technique, avec le groupe Dead Kennedys (dans la chanson « The Man with the Dogs », sur l'album California Über Alles, 1980), puis avec la formation Lard, sur l'album The Power of Lard en 1989: "J'ai coupé des slogans publicitaires dans le Chicago Tribune et nous les avons mélangés suivant la méthode du cut-up de William Burroughs. Nous voulions rendre ça aussi ridicule et absurde que possible » (Jourgensen 2013 : 105). L'emploi de publicités découpées dans les journaux revient à un détournement, c'est-à-dire une réappropriation d'un objet à des fins critiques. Le but recherché, le ridicule et l'absurde, coïncide, dans le punk, avec un sentiment d'absurdité sociale : réponse de la jeunesse à un ordre social injuste, le désordre punk trouve dans le cut-up un moyen d'expression privilégié. Ce sont donc autant les implications idéologiques du cut-up que la méthode elle-même qui déterminent cette filiation entre cut-up et punk. En effet, Olivier PenotLacassagne (2013: 15) explique :

[...] la contre-culture punk [...] affronte en pleine lumière les impasses du moment. Une certaine conception du monde, une « époque du sens » s'achève. Le punk est le reflet de cette déshérence. Sa différence, son irréductibilité viennent de ce déplacement qui nous amène hors des paysages familiers. Le punk a affaire avec la perte, et non plus avec les gains de l'émancipation.

On comprend mieux l'engouement punk pour Burroughs : la perte du sens est un principe moteur dans la trilogie. Il s'agit d'abord d'une perte de la signification au niveau syntaxique, ensuite au niveau diégétique (la trilogie s'achève sans finir, sur une impasse, sur un non-dénouement), enfin une perte de sens comme direction (le retour de certains fragments trouble le sens de la lecture : tout est, littéralement, sens dessus dessous).

À partir des années 1980, plusieurs courants issus du punk se développent, notamment le rock alternatif : à l'origine produit par des labels indépendants, ce genre va connaître un succès commercial considérable dans les années 1990. Et le cut-up, tout expérimental qu'il soit, va de nouveau s'immiscer dans les productions de la culture de masse.

\section{Le rock alternatif}

Dans les années 1990, Burroughs participe à plusieurs projets avec des musiciens rock, comme Tom Waits, pour qui il crée le synopsis de l'opéra rock The Black Rider en 1993. Il 
collabore également avec Kurt Cobain sur l'œuvre The "Priest" They Called Him (1993). L'auteur américain y lit d'une voix monocorde le texte éponyme, tiré de son roman Exterminator!, tandis que Cobain joue un morceau lancinant à la guitare électrique saturée. La participation de Burroughs est en définitive limitée : le texte préexistant est tout au plus réactualisé par la musique rock. Mais l'influence de l'écriture burroughsienne sur Cobain est plus profonde, puisque l'artiste déclare à la même époque : «Mes paroles sont un cut-up total. Je prélève des vers de différents poèmes que j'ai écrits. Je m'appuie sur un thème si je peux, mais parfois je n'ai aucune idée de ce dont parle la chanson » (Derogatis 2001). Le choix de cette écriture du hasard que représente le cut-up n'est pas anodin : le grunge, rock alternatif hérité du punk et du metal, dont Cobain est sans doute le plus célèbre représentant, se caractérise par un état d'esprit à la fois désabusé et révolté. Aussi le cut-up représente-t-il, dans cette perspective, tout autant qu'un refus d'écrire des chansons pour l'industrie culturelle, un paradoxal retrait de sa propre création, laissant le hasard décider du résultat: entre provocation et désengagement, Kurt Cobain trouve dans le cut-up l'expression de ses propres paradoxes.

À la même époque paraît l'album Dead City Radio (1990), comportant dix-sept titres : il s'agit de textes lus par Burroughs et mis en musique par des artistes comme John Cale (membre fondateur du Velvet Underground), Donald Fagen, Lenny Pickett, Chris Stein (du groupe rock Blondie), ou Sonic Youth : ce groupe de rock alternatif, proche du punk, a d'ailleurs été particulièrement inspiré par le cut-up. Le titre " Tuff Gnarl » (Sister, 1987), dont la musique plaisante contraste avec le lexique explicitement sexuel, est le résultat d'un cut-up du fanzine Killer, édité par Thurston Moore ${ }^{4}$, guitariste du groupe. Ce dernier déclare dans un entretien: "ce qui m'a toujours intéressé c'est ce qu'il se passe si on prend des éléments et qu'on les déplace. D'une certaine manière, ça a toujours été le modus operandi de Sonic Youth» (Moore 2014). En effet, l'utilisation du cut-up a été relayée par la presse, notamment à la sortie de l'album Goo, sorti en 1990. Le morceau "Mote », sombre et dissonant, fait vraisemblablement référence au cut-up: dans le dernier couplet, la phrase «And words don't speak just fall across the carpet » («Et les mots ne disent rien, ils tombent juste sur le tapis ») ne manque pas de rappeler un fragment récurrent dans la trilogie Nova - «Word falling» (« Mot tombant »). La «chute des mots" que provoque le cut-up est, dans la trilogie, le moyen de résister à leur emprise ; dans la chanson de Sonic Youth, les mots semblent déjà muets, vides de sens, défaits par l'opération de découpage.

Dans l'introduction à un entretien avec Burroughs, Lee Ranaldo (1998: 78), co-fondateur du groupe, rend hommage à l'écrivain :

Cet homme, qui parlait du langage comme d'un virus, est devenu subliminal, un organisme oblique, qui s'enracine sous la peau culturelle de notre temps. Imaginez un monde sans cut-up, sans sa temporalité desséchée jusqu'à l'os, sans La Machine Molle ni Dr Benway. Imaginez combien d'œuvres vitales et audacieuses de ces dernières décennies, dans tellement de champs, n'auraient pas existé sans lui.

L'artiste souligne ici le caractère "subliminal", presque souterrain de l'influence burroughsienne. Ce faisant, il résume bien la difficulté à isoler précisément ce qui relève d'un usage précis du cut-up de ce qui procède d'une influence plus floue. Car on pourrait citer encore de nombreux groupes et artistes de la scène rock influencés, de près ou de loin, par William Burroughs : pensons aux deux formations rock initiées par le batteur anglais Robert Wyatt, Soft Machine et Matching Mole, dont les noms font référence au premier opus de la trilogie Nova, ou encore au musicien grunge Grant Hart, fondateur du groupe Nova Mob. Les années 1990 voient ainsi se tisser un réseau musical allant du rock 
alternatif au punk, où abondent les références à l'auteur de la trilogie Nova. Thom Yorke, leader du groupe Radiohead, aurait de même utilisé le cut-up sur l'album Kid A, sorti en 2000.

Aussi le cut-up, en irriguant le champ du rock, tend-il à y disparaître et ne restent plus que les déclarations des artistes affirmant avoir procédé sous l'influence du cut-up, sans beaucoup plus de précisions. C'est une des spécificités de ce mouvement de déploiement du cut-up : des années 1970 au tournant du xxI e siècle, il devient progressivement une idée, un symbole, métonymique de son inventeur : le symbole d'une émancipation, plus ou moins politisée suivant les courants et les artistes, mais toujours liée à l'idée d'une opposition à la culture dominante.

\section{Le cut-up, entre avant-garde et contre-culture}

La notion de contre-culture est formalisée en 1968 par le sociologue Theodore Roszak, dans The Making of a Counter Culture, qui présente les mouvements contestataires américains des années 1960 comme guidés par un refus des systèmes de contrôle de la société technocratique. Si Roszak voit dans les années 1970 le déclin de cette contreculture, il n'en demeure pas moins que d'autres, comme le punk, prennent ensuite le relais. Alors que les contre-cultures s'essoufflent et sont peu à peu absorbées par le mainstream, d'autres émergent, grandissant à la fois sur les acquis et les échecs des précédentes. Pour Olivier Penot-Lacassagne (2013: 15) :

[...] plusieurs facteurs expliquent le déclin d'une contre-culture : la modernisation de la société, devenue plus permissive; la mutation du contexte politique, idéologique, économique, national, voire international, qui l'a vu évoluer; la délégitimation soudaine d'imaginaires et de rhétoriques; l'épuisement brutal de récits d'émancipation; son absorption spectaculaire et sa marchandisation; sa dissolution sous-culturelle et sa vulgarisation... Mais la somme de ces éléments n'engendre pas la disparition du principe même de contre-culture.

Ainsi, à chacune de ces mutations contre-culturelles, des Rolling Stones à Radiohead, le cut-up refait surface, comme élément de continuité d'une pensée contestataire. On pourrait aller jusqu'à dire que le cut-up représente lui-même la mutation d'une contreculture plus ancienne, celle des avant-gardes historiques : Jean-Louis Harouel (1994: 6) fait remarquer à ce propos que « la modernité artistique peut être lue comme une contreculture [...], on observe dans des mouvements d'avant-garde aussi importants que Dada ou le surréalisme une haine viscérale de sa propre civilisation, un mépris absolu de l'art et de la culture ». Il y a alors, de Dada au punk rock en passant par le situationnisme, une généalogie de la contestation qu'a d'ailleurs bien montré Greil Marcus dans son célèbre essai Lipstick Traces (1989).

Prolongeant le collage moderniste de Dada, le cut-up incarnerait alors un moment charnière, un pivot entre avant-garde et contre-culture. D'une part, il partage avec la pensée d'avant-garde une certaine recherche d'innovation esthétique: l'emploi du collage (pratique historiquement avant-gardiste) permet la création de nouvelles significations, et la systématisation du cut-up à l'échelle d'un roman procède bien d'une innovation. Mais d'autre part, la technique d'écriture de Burroughs glisse vers le champ contre-culturel, car elle porte en elle cette dimension d'opposition à la culture dominante, du fait que le cut-up est aussi, outre un mode de création innovant, un moyen 
de déconstruire les discours dominants (du pouvoir, de la publicité, des médias en général).

Bien que l'on puisse à certains égards considérer l'avant-garde comme une sorte de contre-culture, des différences subsistent, différences qu'Olivier Penot-Lacassagne (2013 : 4-5) résume ainsi : «à la pointe avant-gardiste, [la contre-culture] oppose le pas de côté ; au dépassement, le déplacement ". C'est d'ailleurs le principe même du cut-up: du déplacement littéral des fragments à travers la trilogie, au déplacement médiatique du cut-up vers la bande sonore ou le film, en passant par le déplacement disciplinaire vers la peinture, la musique ou la poésie, tout dans le cut-up permet une incorporation à la contre-culture, une appropriation par des artistes sensibles à la dimension libératoire du procédé et/ou à son caractère politique.

Les raisons de l'implantation de cette écriture expérimentale dans la contre-culture, et en particulier dans la chanson rock, sont donc à la fois historiques, poétiques, esthétiques et politiques. Historiquement, la diffusion des cut-ups sonores et les nombreuses collaborations de William Burroughs, que nous avons évoquées plus haut, ont permis une réception de son œuvre dans les milieux artistiques de la contre-culture. Victor Bockris, interviewé dans le documentaire consacré à Burroughs, A Man Within, affirme d'ailleurs que «le medium principal de la contre-culture, c'est la collaboration». Le caractère collaboratif du travail de Burroughs (le cut-up est né de son travail avec Gysin) s'est donc naturellement inscrit dans ce champ, car comme le rappelle Timothy S. Murphy (1997 : 207), « la collaboration a toujours servi à Burroughs de méthode pour échapper à la tyrannie du sujet individuel, c'est une manière de créer une "troisième voix" supérieure à celles des collaborateurs ». Dans le cut-up, la troisième voix (the third mind) est le sens inédit qui émerge du collage et qui, sans se cantonner à l'addition des significations des textes préexistants, les dépasse. Plus globalement, la troisième voix constitue le principe actif de l'œuvre collective, qui n'est pas non plus l'addition du travail de deux auteurs, mais une tierce identité qui se fait jour. Elle devient ainsi la voix d'une pensée qui s'émancipe de l'individualité.

Mais plus profondément, il apparaît que la postérité rock du cut-up était en germe dans ses propres mécanismes : tout d'abord, le caractère science-fictionnel de la trilogie Nova rattache d'emblée cette œuvre à une littérature populaire, genre longtemps considéré comme mineur. De plus, l'emploi du magnétophone, moyen technique largement répandu depuis 1950, s'inscrit dans la même logique d'incorporation de la culture populaire à la création littéraire : aussi les fondements mêmes du cut-up s'inscrivent-ils dès le départ dans la culture populaire.

La dimension politique du procédé reste très présente, de Bowie à Sonic Youth: la critique des médias, du discours dominant, du contrôle que les images et les discours exercent sur les individus, sont autant de motifs que les paroliers rock s'approprient à des degrés divers. En germe chez Bowie, ces questions se concrétisent dans le détournement de publicités par Jello Biaffra, puis prennent avec Cobain le tour d'un refus ironique de créer du sens, et avec Sonic Youth une mise en question de la capacité des mots à signifier.

41 Rappelons en outre que le cut-up repose sur une politique de l'écriture. L'objectif explicite d'une "poésie faite par tous", précepte fondateur du cut-up, semble ainsi réalisé : dans la droite ligne de sa logique virale, le cut-up s'est propagé à la chanson populaire et, pour s'y adapter, a muté. Si on ne retrouve pas toujours, dans les paroles inspirées du cut-up, les aspects les plus significatifs ou les plus radicaux de l'écriture 
burroughsienne, l'auteur de la trilogie Nova est néanmoins devenu l'incarnation de la contestation rock dans la mesure où il a mis l'ordre établi en question dans les structures mêmes de la langue. La critique de la société n'émerge plus seulement au niveau thématique, mais irrigue la structure syntaxique et, broyant la linéarité du discours, déconstruit la notion même de création. C'est donc plus globalement une certaine esthétique du désordre qui trouve dans les musiques rock, historiquement contreculturelles, un lieu naturel. Et si l'emploi du procédé n'est pas revendiqué par les artistes en tant que mise en œuvre stricte de la technique burroughsienne, il opère néanmoins comme un «stratagème dissident » (Caveney [1998] 1999 : 202) : le devenir rock du cut-up était donc en quelque sorte inscrit dans son ADN.

Rarement une écriture aussi complexe et radicale que celle de Burroughs a eu un tel retentissement: la revendication de l'emploi de la technique de Burroughs par des auteurs-compositeurs de la culture populaire y a largement contribué. Bien qu'il soit atténué, son potentiel de contestation n'en a pas pour autant été totalement digéré par les rouages de l'industrie culturelle : si l'on considère la dimension critique des différents artistes précédemment mentionnés, leur inquiétude vis-à-vis des médias et de la société consumériste, mais aussi la volonté de libérer l'écriture de chansons d'une certaine linéarité, on voit que les musiques rock, punk et alternatives ont en quelque sorte réactivé l'antagonisme culturel que représentait Burroughs.

Ce constat prend totalement le contre-pied de la critique d'Adorno et Horkheimer ([1947] 1974 : 130) selon laquelle la culture de masse et l'industrie culturelle annihileraient la conscience critique et «n'abouti[rait] qu'à la standardisation et à la production en série ». Dans le cas des chanteurs rock précédemment cités, l'industrie culturelle devient au contraire le vecteur d'un discours contestataire, hérité d'une écriture avant-gardiste expérimentale. En contrepartie, les aspects les plus virulents, les plus politiques du cut-up sont parfois atténués, en particulier dans les années 1970. Pour autant, on ne se trouve pas ici dans le cas d'une industrie qui créerait un objet culturel sans effet social, mais bien dans le cas de contre-cultures qui s'emparent des procédés issus de l'avant-garde et qui, littéralement, les popularisent et les rendent accessibles à un nouveau public.

En se propageant, le cut-up a tissé un réseau contre-culturel qui invite à penser un continuum allant de l'avant-garde dadaïste au rock alternatif. L'examen (non exhaustif) de la généalogie de cette technique d'écriture permet de repenser à la fois l'histoire des pratiques de collage et celle des contre-cultures, moins sous l'angle de ses ruptures que sous celui de ses persistances. Comme exercice critique de réappropriation du langage, le cut-up se reconfigure dans des espaces culturels inédits, se connecte à de nouveaux champs et se trouve remotivé dans de nouveaux contextes. En ce sens, il adopte une logique rhizomique, dans le sens que Deleuze et Guattari $(1980: 29)$ donnent à ce terme : «rhizome américain: beatnick, underground, souterrains, bandes et gangs, poussées latérales successives en connexion immédiate avec un dehors ». Ce dehors est aussi celui de la culture de masse qui, si elle incorpore et aplanit les contestations, ne met jamais fin aux poussées contre-culturelles. La technique d'écriture de Burroughs, œuvrant à la fois dans la culture d'avant-garde et dans la culture populaire, opère ainsi selon un mouvement continu de déterritorialisation - ouverture transdisciplinaire, emprunts, collaborations multiples, sortie du champ strictement littéraire - et de reterritorialisation 
- créations hybrides (entre littérature, peinture et musique), propagation esthétique et idéologique, réinvestissement dans de nouveaux champs, reconfiguration des rapports entre la culture de masse et la culture dite d'élite.

\section{BIBLIOGRAPHIE}

Adorno, Theodore W. et Horkheimer, Max, [1947] 1974, La Dialectique de la raison : fragments philosophiques, trad. Éliane Kaufholz, Paris, Gallimard.

Batt, Noëlle, 1975, L'Écriture de William Burroughs, thèse de troisième cycle d'Études nordaméricaines sous la direction de Pierre Dommergues, Paris, Université Paris 8.

Bockris, Victor, 1981, With William Burroughs. A report from the Bunker, New York, Seaver Books. Burroughs, William S. et Gysin, Brion, 1976, CEuvre croisée, trad. Gérard-Georges Lemaire, Paris, Flammarion.

Burroughs, William Seward, 1994, La Machine molle [1966], Le Ticket qui Explosa [1967], Nova Express [1964], trad. Claude Pélieu et Mary Beach, Paris, Christian Bourgois.

Cavanagh, David, 2010, « Exile! », Uncut Magazine, $\mathrm{n}^{\circ}$ 155, p. 46-60.

Caveney Graham, [1998] 1999, Gentleman Junky, la vie et l'œuvre de William Burroughs, trad. Marc Voline, Paris, Seuil.

Chick, Steve, 2008, Psychic Confusion: The Sonic Youth Story, Londres, Omnibus Press.

Debord, Guy Ernest, 2006, Euvres, Paris, Gallimard, coll. « Quarto ».

Deleuze, Gilles et Guattari, Félix, 1980, Capitalisme et schizophrénie : mille plateaux, Paris, Minuit.

Derogatis, Jim, 2001, « When Nirvana Delivered a Masterpiece », 21 octobre 2001, http://

www.jimdero.com/News2001/GreatOct21Nirvana.htm, consulté le 14 juin 2018.

Harouel, Jean-Louis, 1994, Culture et contre-culture, Paris, PUF.

Jourgensen, Al, 2013, Ministry: The Lost Gospels According to Al Jourgensen, Boston, Da Capo Press.

Lydenberg, Robin et Skerl, Jennie, 1991, William S. Burroughs at the Front. Critical Reception, 1959-1989 , Chicago, Southern Illinois University Press.

Marcus, Greil, [1989] 1998, Lipstick Traces. Une histoire secrète du XXe siècle, trad. Guillaume Godard, Paris, Gallimard, coll. « Folio ».

Miles, Barry, 1995, « Texte de présentation », dans W. S. Burroughs, Call me Burroughs, réédition en CD, Los Angeles, Rhino Records.

Moore, Thurston, 2014, «The Beat Goes On », entretien avec Kevin EG Perry, New Musical Express, 8 février 2014

Murphy, Timothy S., 1997, Wising Up The Marks. The Amodern William S. Burroughs, Los Angeles, University of California Press.

Penot-Lacassagne, Olivier et Bourseiller, Christophe, 2013, Contre-cultures !, Paris, CNRS Éditions. 
Ranaldo, Lee, [1997] 1998, « William Burroughs I-view », dans D. Mahoney, M. Richard et

R. Whitehead (dir.), A Burroughs Compendium: Calling the Toads, Rhode Island, Ring Tarigh, p. 77-93.

Tzara, Tristan, 1996, Dada est tatou. Tout est dada, Paris, G-F Flammarion.

\section{Discographie}

Bowie, David, 1971, Hunky Dory, New York, RCA Records.

Bowie, David, 1972, The Rise and Fall of Ziggy Stardust and the Spiders from Mars, New York, RCA

Records.

Bowie, David, 1977, Heroes, New York, RCA Records.

Burroughs, William S., 1990, Dead City Radio, New York, Island Records.

Burroughs, William S. et Cobain, Kurt, [1993] 2003, The "Priest" They Called Him, Portland, Tim Kerr Records.

Dead Kennedys, 1980, California Über Alles, San Francisco, Alternative Tentacles Records.

Lard, 1989, The Power of Lard, San Francisco, Alternative Tentacles Records.

Sonic Youth, [1987] 1994, Sister, Santa Monica, Geffen Records.

Sonic Youth, 1990, Goo, Santa Monica, Geffen Records.

The Rolling Stones, 1972, Exile on Main St., New York, Atlantic Records.

Waits, Tom, 1993, The Black Rider, New York, Island Record.

\section{Filmographie}

Leyser, Yoni, 2012, A Man Within, Paris, KMBO, 87 minutes.

Yetob, Alan, 1975, Cracked Actor, Londres, BBC, 53 minutes.

\section{NOTES}

1. « Fliday » dans le texte original.

2. En dehors des traductions mentionnées en bibliographie, les textes en anglais cités dans l'article sont traduits par l'auteur.

3. «Prenez un journal. / Prenez des ciseaux. / Choisissez dans ce journal un article ayant la longueur que vous comptez donner à votre poème. / Découpez l'article. / Découpez ensuite avec soin chacun des mots qui forment cet article et mettez-les dans un sac./ Agitez doucement. Sortez ensuite chaque coupure l'une après l'autre. Copiez consciencieusement dans l'ordre où elles ont quitté le sac./ Le poème vous ressemblera » (Tzara [1918] 1996 : 228).

4. Voir à ce sujet : Chick, Steve, Psychic Confusion: The Sonic Youth Story, Omnibus Press, 2008. 


\section{RÉSUMÉS}

Créé en 1959 par William S. Burroughs et Brion Gysin, la technique du cut-up repose sur le découpage et le réagencement de fragments de textes d'origines diverses. Burroughs l'applique notamment dans la trilogie Nova, (The Soft Machine, 1961; The Ticket That Exploded, 1962 ; Nova Express, 1964). D'abord décrié, le cut-up va, dès les années 1970, inspirer de nombreux musiciens rock, s'immisçant ainsi dans la culture populaire. Cet article propose d'analyser les modalités de cette « postérité rock » d'une écriture expérimentale.

Created in 1959 by William S. Burroughs and Brion Gysin, the cut-up technique rests on cutting and assembling scraps of texts from various sources. Burroughs employed it notably in the "Nova trilogy" (The Soft Machine, 1961; The Ticket That Exploded, 1962; Nova Express, 1964). Initially condemned, the cut-up technique inspired many rock musicians and infiltrated mainstream popular culture from the 1970s onward. Therefore, the present article will examine the terms of the "rock posterity" of an experimental writing technique.

\section{INDEX}

Mots-clés : cut-up, Burroughs (William), rock, contre-culture, avant-garde, musique, chanson

Keywords : cut-up, Burroughs (William), rock, counterculture, avant-garde, musique, chanson

\section{AUTEUR}

CLÉMENTINE HOUGUE

Université du Mans, Université Paris 3 - Sorbonne Nouvelle 